ARTICLE

\title{
Monte Carlo Simulation of the Prompt Dose Environment in the National Ignition Facility during Low Yield D-T Shots
}

\author{
Hesham KHATER* and Sandra BRERETON
}

Lawrence Livermore National Laboratory, Livermore, CA 94550, USA

\begin{abstract}
The National Ignition Facility (NIF) at Lawrence Livermore National Laboratory is the world's largest and most powerful laser system for inertial confinement fusion (ICF). The NIF is a 192 laser beam facility that is capable of producing 1.8 MJ, 500 TW of ultraviolet light. During the ignition campaign, the NIF is expected to generate shots with varying fusion yield (up to $20 \mathrm{MJ}$ per shot) and a maximum annual yield of 1,200 MJ. The thicknesses of the different shield doors in the facility were optimized such that the annual dose in the NIF occupied areas is limited to $<50 \mu \mathrm{Sv}$ per $20 \mathrm{MJ}$ shot and $<1 \mathrm{mSv}$ for $1,200 \mathrm{MJ}$ of annual fusion yield. Experiments resulting in neutron yield started in 2010. Monte Carlo simulations have been performed to estimate prompt dose values inside the facility as well as at different locations outside the facility shield walls. Evaluation of the prompt dose environment expected during low yield shots (Category A and B shots) has been completed. Deuterium-Tritium (D-T) shots generating up to $10^{14}$ neutrons per shot are characterized as Category A shots. Due to the low neutron yield, no shield doors other than the primary door connecting the Target Bay and the Diagnostic Building are required. On the other hand, D-T shots generating up to $10^{16}$ neutrons per shot are characterized as Category B shots. At this level, all Target Bay primary shield doors are expected to be in place during the Category B shots. No secondary shield doors are required for either shot category. The Target Chamber shielding, along with Target Bay and Switchyard walls, roofs, and shield doors (when required) will reduce dose values in occupied areas to low levels during these shot campaigns. The maximum dose values in potentially occupied areas are small, estimated at 2 and $7.5 \mu \mathrm{Sv}$ per shot during Category A and B shots, respectively. The dose values inside and outside the NIF are also small and do not pose a hazard to workers, visitors or the public. Results of the Monte Carlo simulation indicate that the current NIF shielding is effective in providing the required radiation protection for all phases of the NIF operation.
\end{abstract}

KEYWORDS: NIF, ICF, radiation safety, Monte Carlo

\section{Introduction}

The National Ignition Facility (NIF) at Lawrence Livermore National Laboratory is the world's largest and most powerful laser system for inertial confinement fusion (ICF). The NIF is a 192 laser beam facility that is capable of producing 1.8 MJ, 500 TW of ultraviolet light. Figure 1 shows a layout of the NIF. The main laser systems are installed in two laser bays inside the Laser and Target Area Building. Each laser bay delivers 96 beams into one of two Switchyards. Sets of turning mirrors in each Switchyard (SY) redirect the beams into the Target Bay. Additional sets of optics in the Target Bay align and focus the beams onto the target in the center of the Target Chamber. The 192 beams enter the Target Chamber through 48 indirect-drive beam ports. Laser beams then enter a metal can (hohlraum) and create thermal $\mathrm{x}$-rays that heat the surface of the D-T capsule.

The Target Bay has a semi-cylindrical design with an inner radius of $15.24-\mathrm{m}, 1.83$-m-thick (6-ft-thick) concrete walls and a $1.37-\mathrm{m}$-thick (4.5-ft-thick) concrete roof. A total of 239 and 121 penetrations are present in the Target Bay and Switchyard walls, respectively. There are seven floor levels within the Target Bay at elevations of $-10.29 \mathrm{~m}$,

*Corresponding author, E-mail: khater1@1lnl.gov

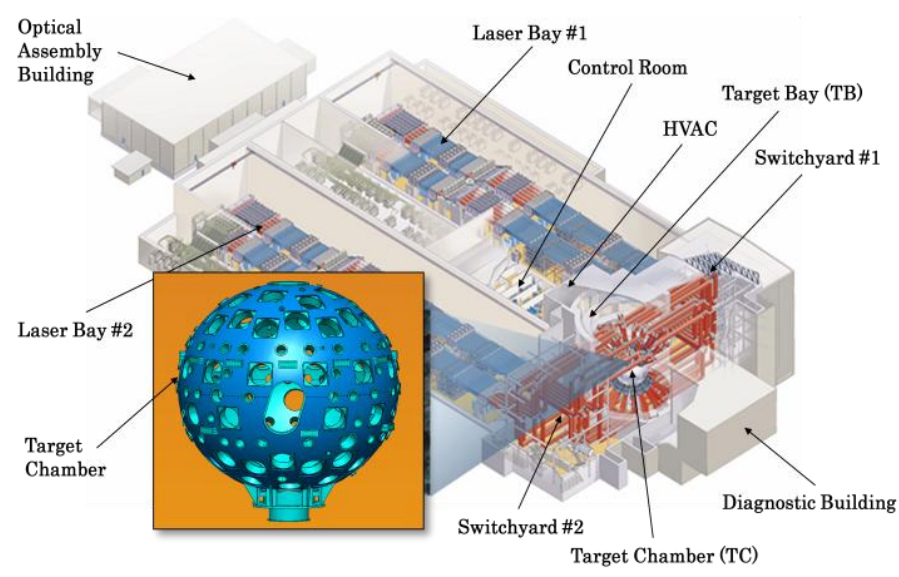

Fig. 1 Layout of the National Ignition Facility

$-6.63 \mathrm{~m},-1.07 \mathrm{~m}, 5.33 \mathrm{~m}, 8.99 \mathrm{~m}, 12.19 \mathrm{~m}$, and $15.39 \mathrm{~m}$ (-33 ft 9 in., $-21 \mathrm{ft} 9$ in., $-3 \mathrm{ft} 6$ in., $17 \mathrm{ft} 6$ in., $29 \mathrm{ft} 6$ in., $40 \mathrm{ft}$ 0 in., and $50 \mathrm{ft} 6 \mathrm{in}$.) with respect to the ground level. The Target Chamber is located in the middle of the Target Bay

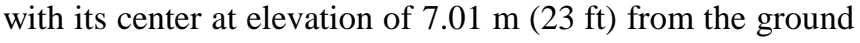
level.

The NIF operation is divided into the following phases: ${ }^{1)}$

1. Phase I includes laser operations with up to 192 beams and shots with no fusion yield. The main radia- 
tion hazard in this phase is caused by $\mathrm{x}$-rays generated due to $3 \omega$ (ultraviolet) laser interactions with different target materials.

2. Phase II includes all Phase I operations and a maximum of 200 Deuterium-Deuterium (D-D) shots per year with maximum yield of $10^{13}$ neutrons/shot.

3. Phase III includes Phase II operations plus a combination of Tritium-Hydrogen-Deuterium (THD) shots and Deuterium-Tritium (D-T) shots for a maximum yield per shot of $30 \mathrm{~kJ}$ ( $\leq 10^{16}$ neutrons) and a maximum annual yield of $30 \mathrm{MJ}\left(10^{19}\right.$ neutrons/yr).

4. Phase IV, which represents full NIF operation, includes Phase III operations and D-T shots with routine $20 \mathrm{MJ}$ yield per shot, and a maximum annual yield of 1,200 MJ.

This paper summarizes results of the radiation safety analysis performed to estimate prompt dose values expected during Phase III of the NIF operation. Results for prompt dose analysis associated with Phases I and II of the NIF operation have been separately published. ${ }^{2,3)}$ Results for prompt dose analysis expected during Phase IV will be separately presented in the future.

\section{Shot Categories}

Based on the expected yield from targets, Phase III operation has been divided into two categories. Targets with maximum neutron yield of $10^{14}$ and $10^{16}$ neutrons/shot will be used during category $\mathrm{A}$ and $\mathrm{B}$ shots, respectively. Areas like the Target Bay, Switchyards, Laser Bays and the two Switchyard elevators are unoccupied by personnel during all type of shots. On the other hand, the Diagnostic Building, the central core (where control room is located), and the visitor center are potentially occupied during shots. The facility shielding has been optimized to meet the NIF radiological design goals as well as the Department of Energy (DOE) limits. The NIF radiological design goal is to limit the maximum prompt dose in any potentially occupied area to less than $50 \mu \mathrm{Sv}$ per shot (i.e., less than the dose that would require posting such an area as a Radiation Area). In addition, the shielding design is aimed at limiting the annual dose to personnel and individuals in the occupied areas as well as to co-located workers and the public to less than $1 \mathrm{mSv}$.

\section{Modeling of the NIF}

A detailed Three-dimensional model of the NIF has been developed using the Monte Carlo radiation transport code, MCNP. ${ }^{4)}$ The Target Chamber is made of a $10-\mathrm{cm}$-thick aluminum wall surrounded by $40-\mathrm{cm}$ of borated concrete. The Target Chamber includes 48 indirect-drive and 24 direct-drive laser beam ports as well as 120 diagnostic ports. All diagnostic and direct-drive ports are assumed to be unshielded and only covered with $\sim 5$-cm-thick port covers made of aluminum alloy. Indirect-drive ports are connected to fully modeled Final Optics Assemblies (FOA). The Target Bay shielding walls are made of 1.83-m-thick concrete, and the typical thickness of a concrete Switchyard wall is $0.991 \mathrm{~m}$. Walls of the Diagnostic Building and two laser

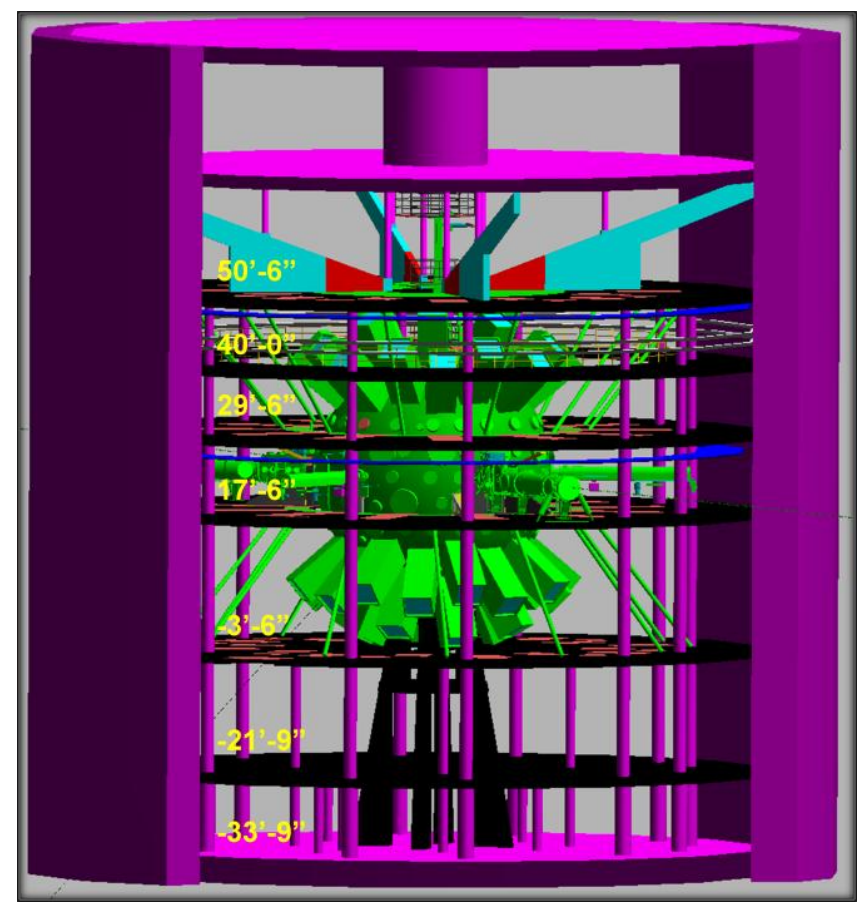

Fig. 2 MCNP model of the NIF Target Bay

bays are made of gypsum.

A total of 19 primary Target Bay doors connect the Target Bay and the two Switchyards. An additional Target Bay door "TOTIM" connects the Target Bay and the Diagnostic Building. The analysis presented in this paper assumes that none of the Target Bay primary shield doors, except for TOTIM, is in place during Category A shots (up to $10^{14}$ neutrons). On the other hand, all primary shield doors are expected to be in place during Category B shots (up to $10^{16}$ neutrons). Additionally, there are 28 secondary doors at points of entry into the Switchyards, including the two facility elevators. This analysis assumed that none of the secondary shield doors will be closed during Category A or $\mathrm{B}$ shots. The shield doors used in the analysis are made of normal concrete with a nominal density of $2.275 \mathrm{~g} / \mathrm{cm}^{3}$, and average volume of iron rebar used in each door is about $1.5 \%$. Except for the TOTIM door, the nominal gap expected at the bottom of each door is $2.54 \mathrm{~cm}$ and $1.27 \mathrm{~cm}$ for primary and secondary shield doors, respectively. The gap at the bottom of the TOTIM door is only $6.35 \mathrm{~mm}$ high. Since all doors utilize multi-step frames, gaps on the top and of sides of each door are fully shadowed by at least one step of concrete (eliminating neutron direct line of sight).

The detailed Target Bay model used in this analysis is shown in Fig. 2. The figure shows details of Target Chamber with all diagnostic and direct-drive ports covered with the aluminum port covers. It also shows the 48 FOAs, Target Bay floors, and other Target Bay concrete support structures. Radiation streaming through the diagnostic and utility penetrations in the Target Bay and Switchyard walls is reduced by installing shielding blocks in the unused portion of these penetrations. In preparation for this phase of the NIF operation, most of the unused utility penetrations (about half of all 


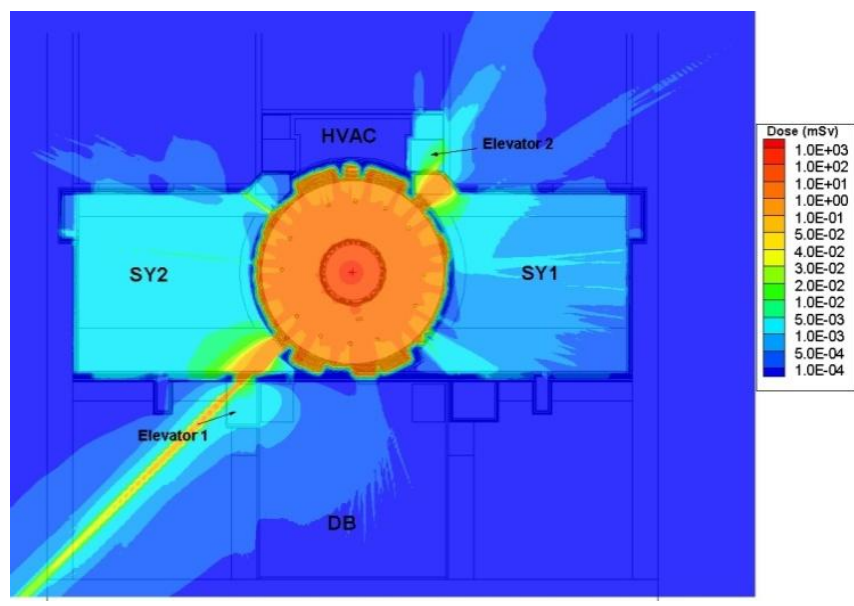

Fig. 3 Prompt dose map of the $5.33 \mathrm{~m}$ (17 ft 6 in.) floor level during Category A shot

penetrations) were shielded with 38 -cm-thick concrete blocks. There are 48 indirect-drive and 8 direct-drive laser beam penetrations in the Target Bay wall. Each penetration is $1.14 \mathrm{~m}$ wide and $1.22 \mathrm{~m}$ high. Since the current NIF configuration does not utilize direct drive ports, a 41-cm-thick concrete block was placed inside each of the direct-drive penetrations.

The neutron cross section data used in the analysis are taken from the FENDL-2.1 cross section database. ${ }^{5)}$ Effective dose values are calculated inside the NIF using the ICRP-74 Anterior-Posterior (AP) neutron fluence-to-dose conversion coefficients. ${ }^{6}$ A detailed D-T neutron source spectrum that is expected from a successful ignition target is used in the form of a volumetric source filling a hohlraum located at Target Chamber Center (TCC). Mesh tallies are used to produce prompt dose maps of the entire facility. The typical Cartesian mesh size is $30 \mathrm{~cm} \times 30 \mathrm{~cm} \times 200 \mathrm{~cm}$. Dose values outside the primary and secondary shield doors (at locations with highest doses) are also calculated. Particle splitting and Russian roulette are used throughout the facility. In addition, to achieve to a better understanding for the source of radiation streaming, particle tracks are followed using the tally cell-flagging feature available with MCNP. The typical statistical errors associated with the calculated dose values in occupied areas are $<10 \%$.

\section{Prompt Dose during Category A Shots}

Prompt dose values (neutron and gamma) are calculated inside the Target Bay, outside all primary Target Bay doors, and outside all secondary doors leading to the two Switchyards. No access is allowed to the inside of the Target Bay, Switchyards, Laser Bays and elevators during shots (exclusion areas).

Figure 3 shows the expected dose values during a Cate-

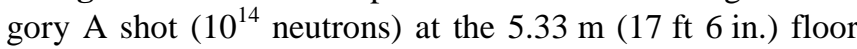
level. This floor level experiences the highest level of radiation due to neutrons streaming out of the Target Chamber through the large number of diagnostic ports located near the Target Chamber waist. The dose values range from a maxi-

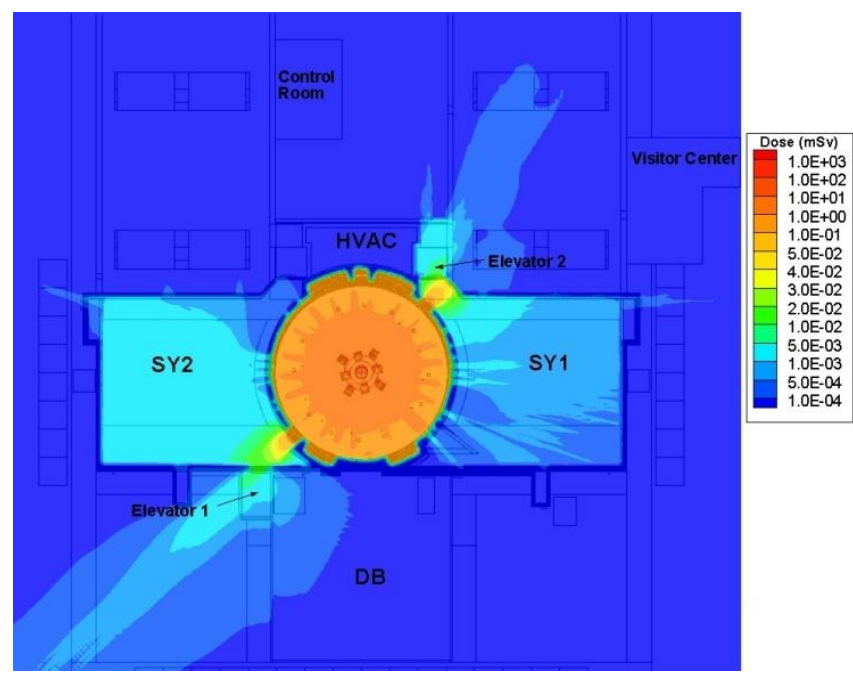

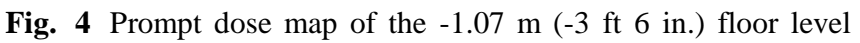
during Category A shot

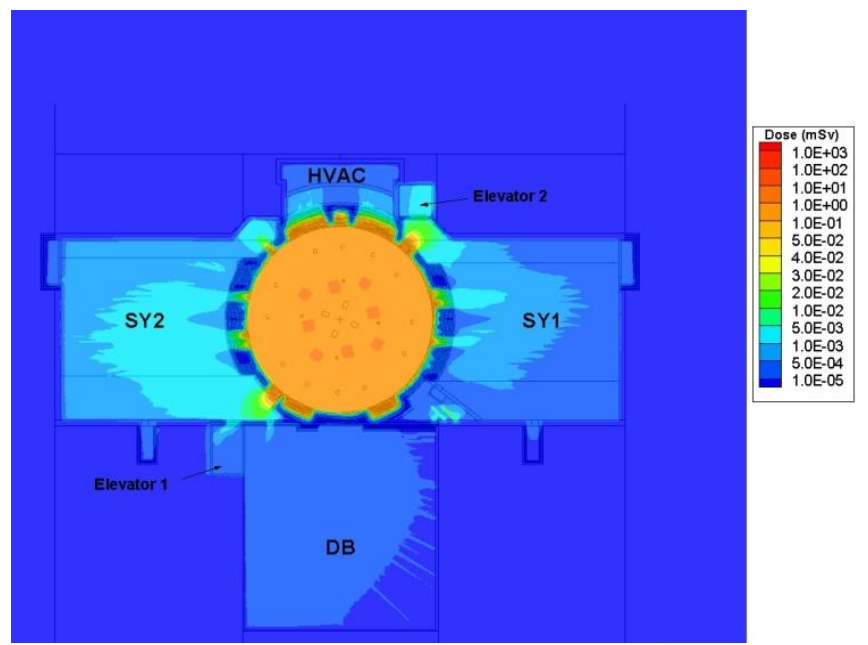

Fig. 5 Prompt dose map of the $-6.63 \mathrm{~m}(-21 \mathrm{ft} 9$ in.) floor level during Category A shot

mum of $12 \mathrm{mSv}$ inside the Target Bay to $0.6 \mathrm{mSv}$ outside the two unshielded primary Target Bay doors (into the unoccupied Switchyards). Much lower dose values are expected in potentially occupied areas. The maximum dose in the occupied Diagnostic Building is only $2 \mu \mathrm{Sv}$. Dose values that are $<0.1 \mu \mathrm{Sv}$ are shown in dark blue on the maps.

Figure 4 shows prompt dose values at ground level. The $-1.07 \mathrm{~m} \mathrm{(-3 \textrm {ft }} 6 \mathrm{in}$.) floor level is considered the ground level for the Target Bay, Switchyards and Diagnostic Building. Dose values inside the Target Bay and Switchyards at this level are about half their values in the $5.33 \mathrm{~m} \mathrm{(17} \mathrm{ft} 6$ in.) floor level. The dose in the occupied Diagnostic Building is also low, $<1 \mu \mathrm{Sv}$. Dose in other occupied areas like the control room and visitor center are on the order of $0.01 \mu \mathrm{Sv}$. Dose in a near-by building at a distance of $\sim 100 \mathrm{~m}$ from Target Chamber center is only $0.003 \mu \mathrm{Sv}$ and the dose at the nearest site boundary (at $350 \mathrm{~m}$ from TCC) is $\sim 2.5 \times 10^{-4}$ $\mu \mathrm{Sv}$ per shot. 


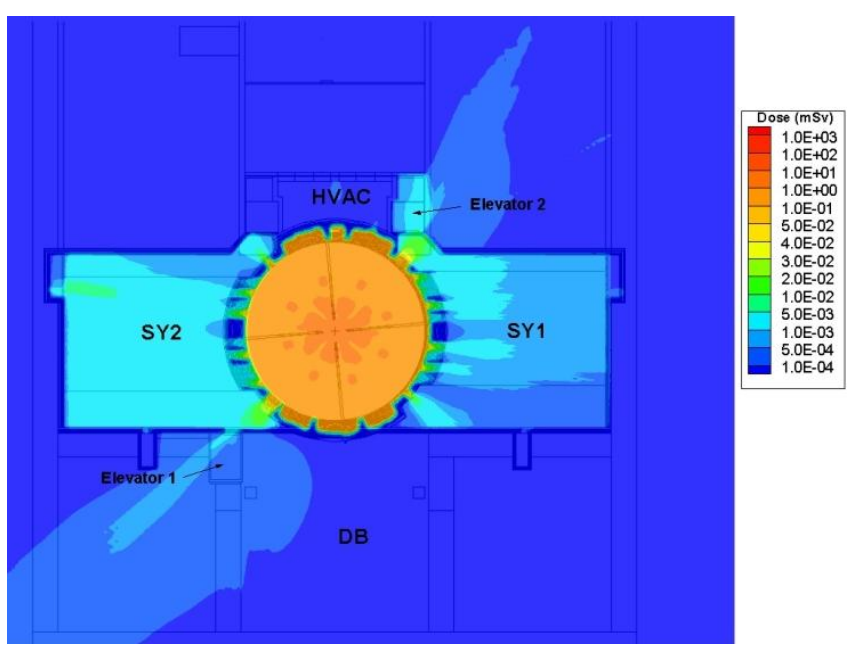

Fig. 6 Prompt dose map of the $15.39 \mathrm{~m}$ (50 ft 6 in.) floor level during Category A shot

The dose values expected in all other floors are lower than the values expected in the $5.33 \mathrm{~m}(17 \mathrm{ft} 6$ in.) floor level. Figures 5 and 6 show the dose maps associated with the

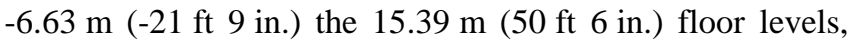
respectively. Since the NIF laser beams pass through the Target Bay wall at these two levels, the wall thickness has been increased at these floor levels from the nominal $1.83 \mathrm{~m}$ to $3.66 \mathrm{~m}$. The reason for increasing the concrete thickness is to allow for additional collimation of neutrons passing through the laser beam penetrations to reduce the radiation environment in the two Switchyards and the rest of the facility. There are 24 indirect-drive and 4 direct-drive laser beam penetrations at each of the two floor levels. Since the current NIF configuration does not utilize direct drive ports, concrete block were placed inside each of the direct-drive penetrations at the two floor level. As shown in the two figures, the radiation streaming through the laser beam penetrations does not produce an increase in the prompt dose values in the occupied Diagnostic Building in case of the $-6.63 \mathrm{~m}$ (-21 ft 9 in.) floor level or the Diagnostic Building

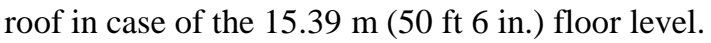

A summary of calculated prompt dose values in all occupied areas is shown in Table 1. The table includes the estimated dose values outside the lower diagnostic mezzanines located at the $2.39 \mathrm{~m}(7 \mathrm{ft} 10 \mathrm{in}$.) and the upper

Table 1 Maximum prompt dose values during Category A shot

\begin{tabular}{lcc}
\hline Location & Floor level & Dose $(\mu \mathrm{Sv})$ \\
\hline Diagnostic Building & $-10.29 \mathrm{~m}(-33 \mathrm{ft} 9$ in. $)$ & 0.45 \\
Diagnostic Building & $-6.63 \mathrm{~m}(-21 \mathrm{ft} 9$ in. $)$ & 1.5 \\
Diagnostic Building & $-1.07 \mathrm{~m}(-3 \mathrm{ft} 6$ in. $)$ & 1 \\
Outside SY1 & Ground & 0.22 \\
Outside SY2 & Ground & 0.24 \\
Control Room & Ground & 0.003 \\
Visitor Center & Ground & 0.013 \\
Diagnostic Building & $2.39 \mathrm{~m}(7 \mathrm{ft} 10$ in. $)$ & 1.5 \\
Diagnostic Building & $5.33 \mathrm{~m}(17 \mathrm{ft} 6$ in. $)$ & 2 \\
Diagnostic Building & $8.99 \mathrm{~m}(29 \mathrm{ft} 6$ in. $)$ & 1.5 \\
Diagnostic Building & $12.19 \mathrm{~m}(40 \mathrm{ft} 0$ in. $)$ & 1.7 \\
\hline
\end{tabular}

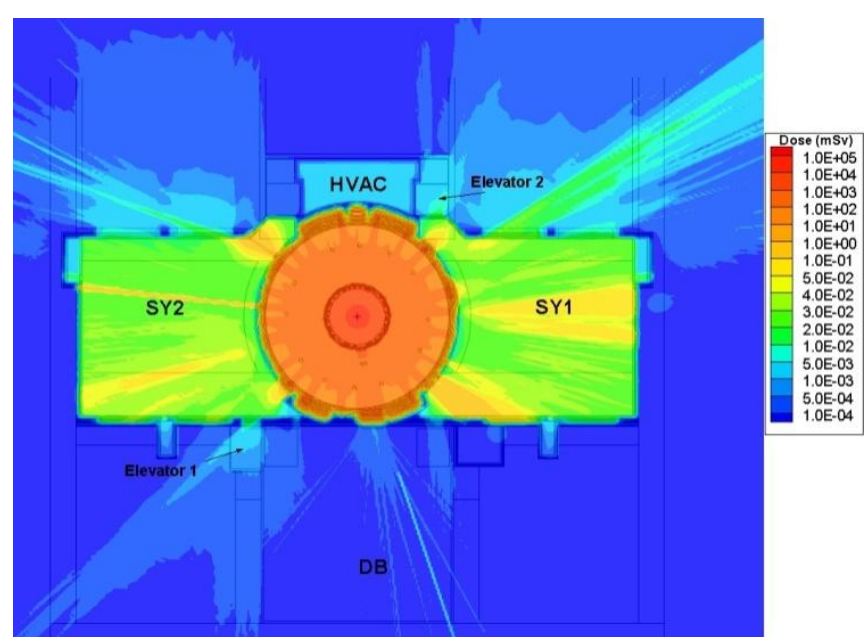

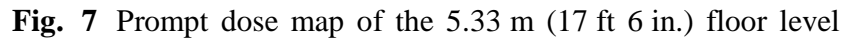
during Category B shot

diagnostic mezzanines located at the $12.19 \mathrm{~m} \mathrm{(40} \mathrm{ft} 0$ in.) floor levels. A maximum dose value of $2 \mu \mathrm{Sv}$ per shot is seen

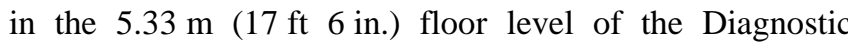
Building. This dose value is well below the NIF design goal limit of $50 \mu \mathrm{Sv}$ per shot. A total of 500 shots could be allowed without exceeding the $1 \mathrm{mSv}$ annual dose limit.

\section{Prompt Dose during Category B Shots}

Category B shots include neutron yields of up to $10^{16}$ neutrons per shot. No change to the facility shielding is expected during this phase except for the requirement that all primary shield doors must be closed during these shots. Closing of the primary shield doors will reduce the radiation streaming into the Switchyards and beyond and hence compensate for the two orders of magnitude increase in the neutron yield. All previously specified shielding for diagnostic and utility penetrations will also remain in place.

Figure 7 shows the expected dose values (neutron and gamma) at the $-5.33 \mathrm{~m}$ (17 ft 6 in.) floor level during a shot. The maximum estimated dose inside the unoccupied Target Bay is about 1.2 Sv. However due to the closing of primary shield doors, the maximum dose in the Switchyards drops to about $0.5 \mathrm{mSv}$. The dose in the occupied Diagnostic Building remains small and is on the order of $1 \mu \mathrm{Sv}$ per shot.

Calculated prompt dose values at ground level are shown in Fig. 8. The dose in the occupied Diagnostic Building remains less than $1 \mu \mathrm{Sv}$ per shot. The highest dose value is calculated outside the two doors connecting the Switchyards to the outside of the building. A maximum dose value of $\sim 7.5 \mathrm{~Sv}$ was calculated at these two locations. Dose in other occupied areas like the control room and visitor center are $0.02 \mu \mathrm{Sv}$ and $0.2 \mu \mathrm{Sv}$ per shot, respectively. Dose values at distance from the facility remain very low. The dose in a near-by building is only $0.03 \mu \mathrm{Sv}$ and the dose at the nearest site boundary is estimated $\sim 0.01 \mu \mathrm{Sv}$ per shot. An additional examination of the dose maps associated with other floor levels indicated that except for the two floor levels leading to the diagnostic mezzanines, the dose values in all other floors remain lower than the values expected in the $5.33 \mathrm{~m}(17 \mathrm{ft}$ 


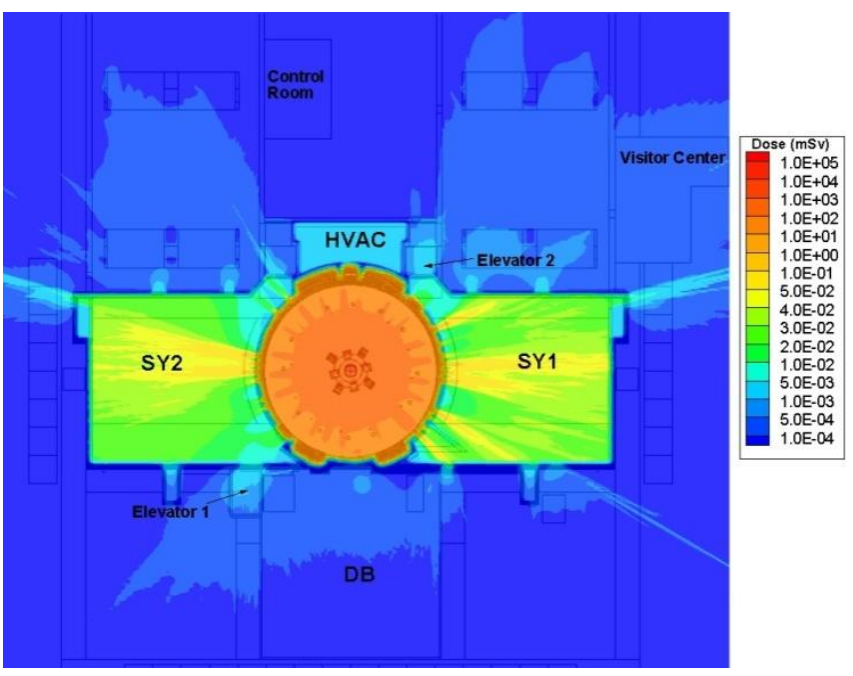

Fig. 8 Prompt dose map of the $-1.07 \mathrm{~m}(-3 \mathrm{ft} 6$ in.) floor level during Category B shot

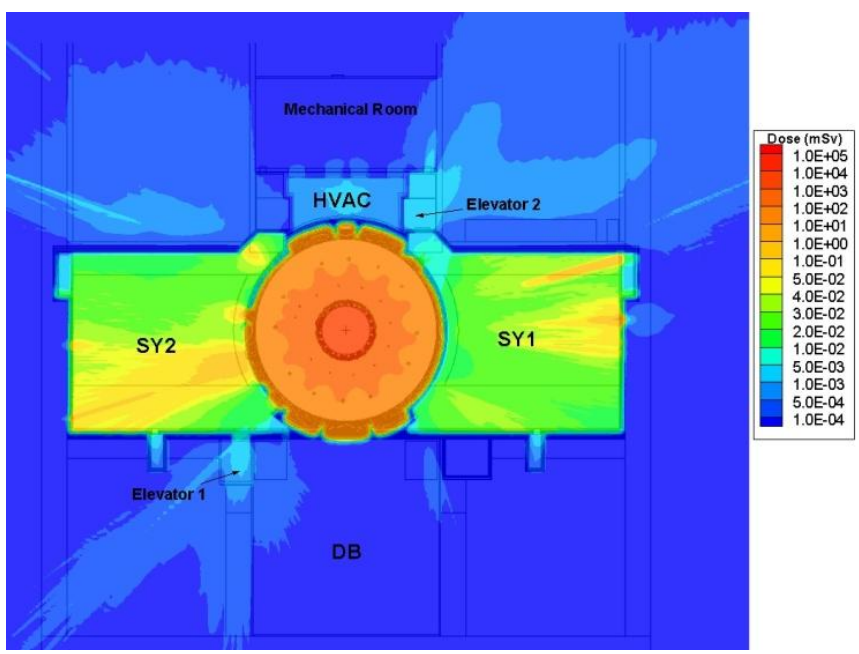

Fig. 9 Prompt dose map of the $8.99 \mathrm{~m}$ ( $29 \mathrm{ft} 6$ in.) floor level during Category B shot

6 in.) floor level. A maximum dose value of $3.2 \mu \mathrm{Sv}$ has been calculated outside the diagnostic mezzanines.

Figures 9 and 10 show the same pattern of low dose values $(<1 \mu \mathrm{Sv}$ per shot) inside the Diagnostic Building in the $8.99 \mathrm{~m}$ ( $29 \mathrm{ft} 6 \mathrm{in}$.) and the $15.39 \mathrm{~m}$ (50 ft 6 in.) floor levels. The figures additionally show that the radiation streaming from the Heating Ventilation and Air Conditioning (HVAC) system into the Mechanical Equipment Rooms (MER) through the air handler penetrations does not result in any significant dose outside these rooms. The two MERs contain the main Target Bay air handlers and are unoccupied during shots. Personnel are kept out of the rooms by access controlled doors.

A summary of calculated prompt dose values in all potentially occupied areas is shown in Table 2. With all primary doors closed the maximum prompt dose value in the Diagnostic Building and outside the facility are 3.2 and $7.5 \mu \mathrm{Sv}$ per shot, respectively. All dose values in potentially occupied areas are below the $50 \mu \mathrm{Sv}$ NIF design goal limit. In

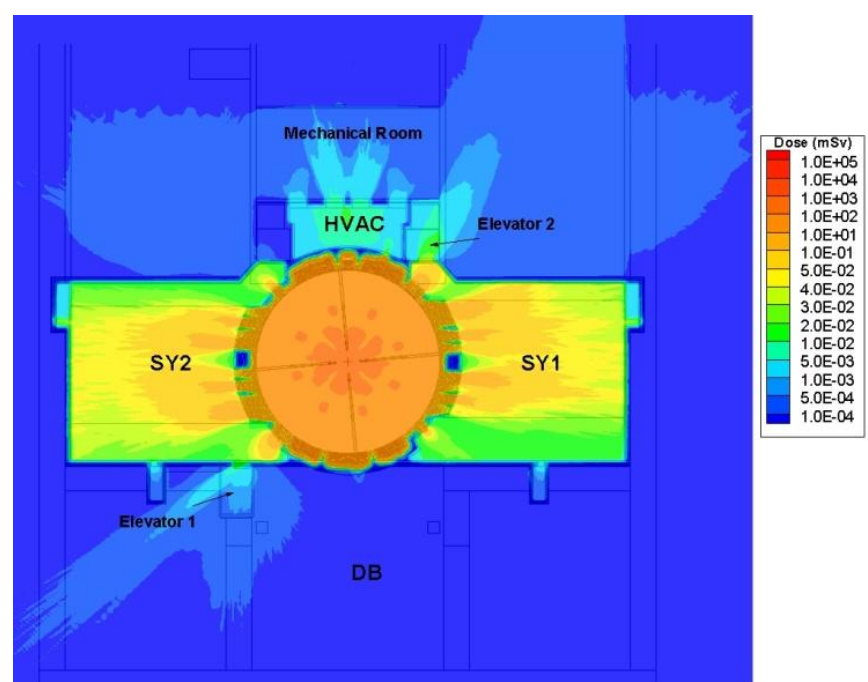

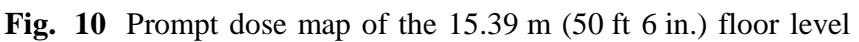
during Category B shot

Table 2 Maximum prompt dose values during Category B shot

\begin{tabular}{lcc}
\hline Location & Floor level & Dose $(\mu \mathrm{Sv})$ \\
\hline Diagnostic Building & $-10.29 \mathrm{~m}(-33 \mathrm{ft} 9 \mathrm{in})$. & 0.32 \\
Diagnostic Building & $-6.63 \mathrm{~m}(-21 \mathrm{ft} 9 \mathrm{in})$. & 0.83 \\
Diagnostic Building & $-1.07 \mathrm{~m}(-3 \mathrm{ft} 6$ in. $)$ & 0.6 \\
Outside SY1 & Ground & 7.3 \\
Outside SY2 & Ground & 7.5 \\
Control Room & Ground & 0.02 \\
Visitor Center & Ground & 0.2 \\
Diagnostic Building & $2.39 \mathrm{~m}(7 \mathrm{ft} 10 \mathrm{in})$. & 3.2 \\
Diagnostic Building & $5.33 \mathrm{~m}(17 \mathrm{ft} 6 \mathrm{in})$. & 1 \\
Diagnostic Building & $8.99 \mathrm{~m}(29 \mathrm{ft} 6$ in. $)$ & 0.5 \\
Diagnostic Building & $12.19 \mathrm{~m}(40 \mathrm{ft} 0$ in. $)$ & 3.2 \\
\hline
\end{tabular}

addition, a total of 130 shots could be allowed without exceeding the $1 \mathrm{mSv}$ annual dose limit. If needed, more shots could be allowed by closing some of the secondary shield doors.

\section{Conclusion}

Detailed analyses of expected prompt dose values during Phase III of the NIF operation have been completed. Targets with maximum neutron yield of $10^{14}$ and $10^{16}$ neutrons will be used during Category A and B shots, respectively. No shield doors other than the TOTIM door are required to be closed for Category A shots. On the other hand, all Target Bay primary shield doors are expected to be in place during Category B shots. No secondary shield doors are required for any of the shots. The maximum dose values inside potentially occupied areas are small, estimated at 2 and $7.5 \mu \mathrm{Sv}$ per shot during the Category A and B shots, respectively. All of the calculated dose values easily meet the DOE requirements related to personnel safety. In conclusion, the dose values inside and outside the NIF during low yield D-T shots are small and do not pose a hazard to workers, visitors or the public. 


\section{Acknowledgment}

This work performed under the auspices of the U.S. Department of Energy by Lawrence Livermore National Laboratory under Contract DE-AC52-07NA27344.

\section{References}

1) Tier 2 Safety Basis Document for the Building 581-582 Complex, NIF-5019666, Rev. 1.1, Lawrence Livermore National Laboratory (2010).

2) H. Khater, S. Brereton, M. Singh, "Shielding Analysis for X-ray Sources Generated in Target Chamber of the National Ignition Facility," Nucl. Technol., 168[2], 381-386 (2009).
3) H. Khater et al.; "Evaluation of Prompt Dose Environment in the National Ignition Facility during D-D and THD Shots," Fusion Sci. Technol., 56[2], 697-701 (2009).

4) X-5 Monte Carlo Team, MCNP - A General Monte Carlo $N$-Particle Transport Code, Version 5, LA-UR-03-1987, Los Alamos National Laboratory (LANL) (2003).

5) D. L. Aldama, A.Trkov, FENDL-2.1: Evaluated Nuclear Data Library for Fusion Applications, INDC(NDS)-467, International Atomic Energy Agency (2004).

6) International Commission on Radiological Protection, Conversion Coefficients for use in Radiological Protection against External Radiation, ICRP Publication 74, Ann. ICRP26, Pergamon Press (1996). 